\title{
DIALECT NAMES OF HOLIDAYS AND RITUALS AS A REFLECTION OF THE CULTURAL AND HISTORICAL TRADITIONS OF THE RUSSIAN PEOPLE
}

\author{
Elvira N. Akimova \\ Pushkin State Russian Language Institute, Moscow, Russia \\ Tatiana I. Mochalova \\ National Research Ogarev Mordovia State University, Saransk, Russia
}

\begin{abstract}
The article studies lexical and phraseological units nominating holidays and ceremonies in Russian dialects, which are spoken on the territory of the Republic of Mordovia. The specificity of nominative processes associated with the naming of a fact that is significant from linguistic and cultural point of view, is determined. The research is carried out on the material taken from the Dictionary of Russian dialects on the territory of the Republic of Mordovia. It has been found that in Russian dialects, the names of religious holidays, which are dedicated to the most revered saints, or the holidays related to a certain time of the year, are actively used. The surviving holidays reproduce elements of the most ancient customs associated with the worship of human deities, the cult of vegetation, water and fire, which magical powers were attributed to. The names of rituals represent a special layer in the dialect corpus. The most illustrative represented are the funeral rite and the rite of baptism. All these rituals are of great importance in the life of the people, since they symbolize a change in the status of a person, his transition from one state to another. The nominations of different phases of wedding ceremony are noted to be most numerous, while funeral and baptizing rites are less representative. The study showed that the names of holidays and rituals in Russian folk dialects reflect cultural and historical traditions, beliefs, customs of representatives of a territorially closed society. They perform peculiar means of representing the ethnic and cultural consciousness of the people.
\end{abstract}

Key words: dialect, vocabulary, phraseology, semantics, nomination, cultural linguistics.

Citation. Akimova E.N., Mochalova T.I. Dialect Names of Holidays and Rituals as a Reflection of the Cultural and Historical Traditions of the Russian People. Vestnik Volgogradskogo gosudarstvennogo universiteta. Seriya 2. Yazykoznanie [Science Journal of Volgograd State University. Linguistics], 2021, vol. 20, no. 1, pp. 17-31. (in Russian). DOI: https://doi.org/10.15688/jvolsu2.2021.1.2

\section{ДИАЛЕКТНЫЕ НАИМЕНОВАНИЯ ПРАЗДНИКОВ И ОБРЯДОВ КАК ОТРАЖЕНИЕ КУЛЬТУРНО-ИСТОРИЧЕСКИХ ТРАДИЦИЙ РУССКОГО НАРОДА}

\author{
Эльвира Николаевна Акимова
}

Государственный институт русского языка им. А.С. Пушкина, г. Москва, Россия

Татьяна Ивановна Мочалова

Национальный исследовательский Мордовский государственный университет им. Н.П. Огарева, г. Саранск, Россия 


\section{РАЗВИТИЕ И ФУНКЦИОНИРОВАНИЕ РУССКОГО ЯЗЫКА}

Аннотация. В работе охарактеризованы языковые единицы, номинирующие праздники и обряды в русских народных говорах, бытующих на территории Мордовии. Определена специфика номинативных процессов, связанных с фиксацией в языке значимого в лингвокультурном плане факта. Исследование проводится на материале «Словаря русских говоров на территории Республики Мордовия». Установлено, что в русских говорах активно употребляются наименования религиозных праздников, посвященных наиболее почитаемым святым, и праздников, относящихся к тому или иному времени года. Выявлено, что сохранившиеся праздники воспроизводят элементы древнейших обычаев, связанных с поклонением божествам, культом растительности, воды и огня, которым приписывали магическую силу. Определено, что особый пласт в составе диалектного корпуса представляют наименования обрядов, поскольку они имеют важнейшее значение в жизни народа, символизируя изменение статуса человека, переход его из одного состояния в другое. Разнообразны номинации этапов свадебного обряда, менее репрезентативны похоронно-поминальный обряд и обряд крещения. Исследование показало, что названия праздников и обрядов отражают культурноисторические традиции, верования, обычаи представителей территориально замкнутого социума, являются своеобразными способами репрезентации этнокультурного сознания народа.

Ключевые слова: диалект, лексика, фразеология, семантика, номинация, лингвокультурология.

Цитирование. Акимова Э. Н., Мочалова Т. И. Диалектные наименования праздников и обрядов как отражение культурно-исторических традиций русского народа // Вестник Волгоградского государственного университета. Серия 2, Языкознание. - 2021. - Т. 20, № 1. - C. 17-31. - DOI: https://doi.org/10.15688/ jvolsu2.2021.1.2

\section{Введение}

Этнический облик духовной культуры в конкретный период развития того или иного народа отражается в языке. Ю.М. Лотман и Б.А. Успенский справедливо отмечают, что «в реальном историческом функционировании язык и культура неотделимы: невозможно существование языка, который не был бы погружен в контекст культуры, и культуры, которая не имела бы в центре себя структуру типа естественного языка» [Лотман, Успенский, 1971, с. 146]. Язык является посредником, механизмом накопления и трансляции культурно-исторических знаний и опыта, который складывается у людей разных национальностей в процессе постижения ими многообразия мира. Однако, по словам Л.М. Штейнгарт, самым мощным средством формирования мировидения, средством влияния на формирование сознания, образа мыслей является культура, или национально-культурная специфика определенной лингвокультурной общности [Штейнгарт, 2006, с. 12].

Наиболее репрезентативны в плане отражения внешних условий жизни, ментальных представлений человека и его поведенческих реакций лексические и фразеологические единицы, называющие календарные праздники и обрядовые действия, поскольку они своими истоками уходят в глубокую древность, отражают образ мира предков, куль- турно-исторические традиции этноса. Обрядовая диалектная лексика и фразеология, сохраняющая сакральные черты самобытной народной культуры, неоднократно становилась объектом этнолингвистических, культурологических и историко-этнографических исследований. Так, в работах отечественных лингвистов представлено изучение свадебного обряда на материале различных говоров [Гайсина, 2007; Гура, 2012; Житникова, 2006; Миронович, 2012; Фомичева, 2012; Чухарева, 1978; и др.]. Внимание исследователей привлекает календарная лексика, связанная с различными христианскими праздниками, поскольку она до настоящего времени сохранила в говорах черты ушедших и уходящих верований, примет, традиций русского народа [Байбурин, 1993; Банкова, 1998; Бахвалова, 2015; Зубова, 2006; Костромичёва, 2007; Кузнецова, 1999; Меркулова, 1994; Тихомирова, 2008; и др.].

Объектом нашего исследования являются лексические и фразеологические единицы, номинирующие праздники и обряды в территориально ограниченном социуме Республике Мордовия. Заметим, что на материале русских говоров Мордовии диалектная фразеология изучалась в этнолингвистическом и лингвокультурологическом аспектах [Акимова, Маслова, Мочалова, 2014; Маслова, Мочалова, 2013; Человек..., 2015], а также с точки зрения репрезентации в ней 
языческого и христианского мировоззрения [Мочалова, Маслова, 2014]. Как мы уже отмечали, анализ таких диалектных единиц становится особо значимым при изучении истории культуры всего народа, поскольку наименования артефактов-предметов материальной культуры, емкая образная характеристика обрядов не только содержат лингвистическую информацию, но и дают представление о разных сторонах жизни и деятельности русского человека конкретного региона, в частности территории Мордовии [Акимова, Маслова, Мочалова, 2014, с. 97].

Вместе с тем наименования календарных праздников и народных обрядов, функционирующие в русских говорах Мордовии и являющиеся региональным вариантом славянских культурно-исторических традиций, продолжают оставаться недостаточно изученными и представляет несомненный интерес для дальнейших лингвистических изысканий.

\section{Материал и методы}

Материалом исследования послужили языковые единицы, извлеченные в результате сплошной выборки из «Словаря русских говоров на территории Республики Мордовия». При разработке проблемы и для реализации цели исследования использовались как общенаучные (обобщение, абстрагирование, формализация, анализ, синтез), так и собственно лингвистические методы. Применялся описательный метод для научного представления языкового материала; метод компонентного анализа языковых единиц - при установлении системных иерархических связей между ними; метод контекстного анализа - при выяснении плана содержания рассматриваемых слов и устойчивых сочетаний. Изучаемые лексические и фразеологические единицы охарактеризованы в зависимости от наличия в их смысловой структуре интегральных и дифференциальных компонентов значения. Кроме того, в работе при рассмотрении наименований праздников и обрядов был использован метод лингвокультурологической интерпретации, основанный на анализе языкового материала с привлечением сведений по истории, культуре, социальной организации сообщества.

\section{Результаты и обсуждение}

В русских говорах на территории Республики Мордовия представлен уникальный лексический и фразеологический корпус, номинирующий календарные праздники, а также связанные с ними обычаи, поверья, верования славян. Разнообразный фактический материал свидетельствует о том, что «календарные праздники как часть традиционной культуры тесно связаны с культурно-хозяйственными и культурно-этническими процессами и представляют собой сплав реального, основанного на богатейшем эмпирическом опыте, и ирреального - синкретизма верований, элементов древних обрядовых культов, местных мифологических преданий и пр.» [Кузнецова, 1999]. Можно говорить о двух разновидностях календарных праздников: во-первых, религиозные праздники, посвященные какому-либо святому; вовторых, традиционные праздники, приуроченные к какому-то событию либо времени года.

Повседневная крестьянская жизнь была тяжелой, изнурительной, постоянный физический труд отнимал здоровье и силы, ежедневный рацион сельского населения не отличался обилием и разнообразием блюд. Поэтому праздника в селах с нетерпением ждали не только дети, но и взрослые, в эти дни устраивались массовые гуляния с хороводами, песнями и плясками, сезонными играми и забавами, во всех домах готовились традиционные кушанья. Неслучайно в русских говорах сохранились наименования таусень, ${ }^{2}$ усенька во 2-м знач., ${ }^{1}$ maусина, обозначающие обряд прославления песнями самого праздника (обычно Рождества или Крещения), а также называющие используемую для этого песню, коляду:

(1) Пь сиделкъм хадили, таусинь кричали (Майдан, Старошайговский район);

(2) С таусиним мы пъ домам ходили, деньги, пироги събирали (Кергуды, Ичалковский район).

Непосредственно процесс прославления праздника песнями обозначал глагол mayсенькать.

\section{Наименования религиозных праздников}

Славянские обычаи и традиции берут свое начало в глубокой древности, и каждое 


\section{РАЗВИТИЕ И ФУНКЦИОНИРОВАНИЕ РУССКОГО ЯЗЫКА}

ритуальное действие имеет особый символический смысл. Так, человек всегда обращался за помощью к высшим силам, искал у них покровительства. Неслучайно в исследуемых говорах представлены многочисленные названия церковных праздников в честь почитаемых святых. Эти праздники отмечаются в строго фиксированный день или могут быть переходящими, не имеющими постоянной даты.

Разнообразные христианские праздники связаны с различными этапами земной жизни Господа Иисуса Христа и Божией Матери. В православной традиции центральной фигурой является Иисус Христос, учению которого следуют верующие, к которому обращаются с молитвами, с которым делятся сокровенными мыслями, имя которого прославляют. Весной в честь Воскресения Иисуса Христа празднуется главный и один из любимых христианских праздников - Пасха. В говорах Мордовии зафиксирован лексикофонетический диалектизм Па́ска. Этому религиозному празднику предшествует Великий пост, накануне праздника женщины тщательно убирают жилище, готовят к этому дню много символических угощений:

(3) Датай их маль, паскъх-ть быват? Што ни гот, то Паскъ. У бабъх-тъ пирит Паскъй самъ работь: избу вымыть надъ, аклиить, шаблы фсе пиримыть. Хватат дялох-ть (Каймар, Краснослободский район).

Пасхальная неделя завершается omданьём - последним днем Пасхи:

(4) Паскь прайдёт, а патом быват адданье Паски (Стародевичье, Ельниковский район);

(5) В адданьё Христос аддалилси па лесницъ (Михайловское, Ковылкинский район).

Одним из двенадцати главных праздников православной церкви является Вознесение Господне, который отмечается на сороковой день после Пасхи и имеет для верующих важное значение. В этот день было принято ходить в церковь на службу, чтобы помолиться о здравии и благополучии всех членов семьи, поскольку в соответствии с религиозными представлениями считалось, что в этот праздник Господь выслушивает просьбы людей и исполняет их. В русских говорах Мордовии зафикси- рованы вариативные наименования этого праздника: Взвесеньё, Взнесеньё, Звесеньё - 'церковный праздник Вознесение':

(6) Бывалъчи Взнисиньё празнъвъли, таперичи нет (Пятина, Ромодановский район).

Важным атрибутом этого праздника была выпечка в форме лесенки, символизирующей путь на небо:

(7) Нъ Взвисиньё пякут лесинки из муки с кашъй (Михайловское, Ковылкинский район).

Фразеологическая единица Сдвиженья день номинирует религиозный праздник Воздвиженье Креста Господня, который является непереходящим и всегда отмечается 27 сентября:

(8) Здвижьнья день-значит, усё с полю здвинулъсь. На Здвижънья день ни должон снек итить (Подлесная Ивановка, Торбеевский район).

На Руси этот праздник объединял в себе церковные и народные традиции. Издревле существовал обычай устанавливать в этот день небольшие часовни, придорожные кресты, обходить с иконой поля и молиться о будущем урожае.

Церковный праздник Крещения Христа отмечается 19 января после череды новогодних праздников и называется в народной среде Кщенье. Он связан с культом воды, ее очищающей силой, избавляющей от грехов и дарующей здоровье, поэтому, несмотря на мороз, проходило массовое погружение людей в прорубь:

(9) На Кщенья марос-тъ сильный был, а атец мой ф пролуби купалси (Куликово, Тенгьгушевский район).

Почитаемый на Руси праздник Введения во храм Пресвятой Богородицы сокращенно называли Введением. В русских говорах Мордовии зафиксировано наименование введеньё - 'религиозный праздник Введение в храм Богородицы (21 ноября по старому стилю)'. У славян этот праздник ассоциировался с наступлением зимы, поскольку проходили гулянья, зимние игры и первые катания на санях, по этому дню судили о предстоящей по- 
годе и будущем урожае. Заметим, что иллюстративный материал показывает утрату актуальности и массовости проведения этого праздника в современной деревне:

(10) Ввидиньё - бальшой празник, дъ сичяс ыво никто ни пъчитат (Кулишейка, Рузаевский район).

Религиозный праздник Рождества Богородицы ежегодно отмечается православными верующими 21 сентября и называется в русских говорах Мордовии адовский праздник. В народной среде не сохранилось сведений об истории возникновения такого наименования:

(11) Празник Ръжоства Бъгородицы нъзывают адъфским празникъм (Суподеевка, Ардатовский район).

Несколько христианских праздников сельские жители отмечают в августе: яблочный спас - 'христианский праздник Преображение Господне (19 августа), после которого разрешалось есть яблоки', успленье 'праздник Успения Пресвятой Богородицы (28 августа)'. Каждый из этих праздников связан с приемом какой-либо символической пищи. Яблочный спас ассоциируется с первым урожаем плодов, с созреванием яблок:

(12) Ябльки нъчинают есть с ябльшнъвъ спасъ (Шаверки, Краснослободский район).

Доедая освященное в церкви яблоко, принято было загадывать желание.

На Успленье готовили каши и пекли хлеб из муки и крупы нового урожая:

(13) Сначаль идёт успленскъй пост две недели, потом 28 августа будит Успленья, ръзговляюццъ кашъй (Суподеевка, Ардатовский район).

В церковной традиции особо почитался святой Николай Чудотворец, который воспринимался на Руси как покровитель русского народа и крестьянский заступник. В диалектной среде зафиксирован народный вариант наименования этого праздника - Микола. Почти до начала XIX в. Николины дни во многих русских деревнях были престольными праздниками, считались важнейшими после Пасхи. Они отмечались зимой и вес- ной: 19 декабря (Никола Зимний, Холодный) и 22 мая (Никола Вешний; Теплый, или Летний), поэтому и в исследуемом фразеологическом корпусе соответственно встречаются наименования вёшняя Микола и зимняя Микола:

(14) У нас две Миколы: зимния Миколь и вёшния Миколь, празники этъ (Никольское, Торбеевский район).

В русских говорах на территории Мордовии употребляются словообразовательные варианты Кузьминка, Кузьминки, Кузьмушка, Кузьминки, называющие религиозный праздник, который отмечается 1 ноября по старому стилю, - День Кузьмы и Демьяна. По мнению исследователей, «особое внимание к этим святым в сельской среде объясняется тем, что святые Кузьма и Демьян славились как мастера и труженики, покровители семейного очага и супружеского счастья» [Маслова, Мочалова, 2013, c. 63]. Носители диалекта отмечают значимость этого праздника, сопровождавшегося песнями и плясками, народными гуляньями:

(15) Вот Кузьмишник тады был, песни пели, дефки плясали (Такушево, Тенгьгушевский район);

(16) Събирёмси мы нъ Кузьминку и давай песни петь (Ключарёво, Рузаевский район).

Интересен тот факт, что жители разных сел указывают на важность данного события в большей степени для девушек или парней, поскольку на таких народных гуляниях молодые люди знакомились и впоследствии создавали семьи:

(17) А Кузьминкъ - эть для девьк празник был (Рождествено, Ичалковский район);

(18) Парни ждуг ни даждуццъ Кузьмушки (Куликово, Тенгьгушевский район).

Устойчивое сочетание Кузьму сидеть характеризует особенности проведения церковного праздника Кузьмы и Демьяна: с вечера и до рассвета деревенская молодежь собиралась на посиделки в большой избе, в которой девушки готовили угощения и приглашали к столу парней:

(19) Кузьму сидеть ребятъ и дефки па осени събирались (Марьяновка, Большеберезниковский район). 


\section{РАЗВИТИЕ И ФУНКЦИОНИРОВАНИЕ РУССКОГО ЯЗЫКА}

Принято было в это день устраивать ccыnчину - складчину перед церковным праздником Кузьмы и Демьяна, в которой участвовали только девушки:

(20) Бывальчи мы и ни слыхали пра празник 8 Мартъ, заместь иво у нас был свой - Кузьминкъ. Как патходит время, устраивъм ссыпчинку (Смольково, Лямбирский район).

День Святой Троицы - важный православный праздник, который верующие отмечают на пятидесятый день после Пасхи и называют его также Пятидесятницей. В русских говорах Мордовии зафиксировано такое название этого праздника, как седмица. Дата Пасхи ежегодно меняется, и Троица, соответственно, не имеет закрепленного дня. На Троицу традиционно храмы украшают ветвями и травой, при этом зеленый цвет символизирует обновление. Обычай плести венки и водить хороводы в лесу в Троицын день номинирует в локальной лингвокультуре фразеологизм идти под венки. Троицын день всегда сопровождался праздничным гуляньем в честь проводов весны, которые в деревнях называли люлё, полюлё, полелё. Этот праздник был ожидаемым в народе, сельские жители наряжались, пели песни, водили хороводы:

(21) На Троицу фсягда пълюлё быват. Самъ лутшъ нъдявали, када ф пълюлё-ть хадили (Соколов Гарт, Чамзинский район);

(22) Ф пълюлё, бывалъ, в лес хадили дъ фсё песни пели, хъраводы вадили. И стърики, и дети ждали пълилё, фсем хательсь виселья, с нитирпеньим ждали (Ключарёво, Рузаевский район).

До принятия христианства в славянском календаре отмечался Семик, символизирующий переход от весны к лету. В исследуемых говорах сохранилось упоминание об этом празднике (семийка, ${ }^{l}$ семишник, семик - 'весенний праздник в четверг перед Троицей’) и о существовавшем культе растительности: березовыми ветками украшали жилище, ходили в лес, наряжали березу, водили вокруг нее хороводы, пели песни, устраивали праздничную трапезу:

(23) Нъ Симик ходют в лес, зъвивают вянки (Покрышкино, Ромодановский район).
В крестьянской среде существовал особый обычай, который назывался гра́нки cmáвить: за три дня до Троицы на дорогах возводились преграды из бревен и плетней:

(24) У нас и сицас гранки ставют. Сиводни увидити, как рабяты будуг гранки ставить (Петровка, Дубенский район).

В исследуемых говорах зафиксированы наименования религиозного праздника Преполовение: Половеньё, Прополвеньё. Преполовение Святой Пятидесятницы - это один из древнейших христианских праздников, называющих половину срока, середину по времени между двумя церковными праздниками Пасхой и Троицей. В традиционной русской культуре после этого праздника можно было собирать грибы, идти на кладбище, что подтверждает исследуемый материал:

(25) Скоръ Пълъвиньё, нъ магилки пайдём (Муравлянка, Ельниковский район);

(26) Вот прайдёт Прыъълвиньё, зъ грибами пайдём (Павловка, Лямбирский район).

В народном сознании маркировались также временные отрезки, обозначающие промежутки между двумя большими религиозными праздниками: пути́на во 2-м знач. - 'отрезок времени между Масленицей и Пасхой; Великий пост', свечки - 'промежуток времени от Рождества до Крещения, святки’:

(27) А путины-ть срокъм большыи были. Во время путины-ть мы ф Самару ездили (Енгалычево, Дубенский район).

В традиционной русской культуре и в православной традиции обязательными элементами были различного рода ограничения верующих для очищения духа, отречения от всего греховного. Диалектная лексическая единица питиньё в 1-м знач. служит у верующих для обозначения церковного наказания - епитимий. Верующие в обязательном порядке исполняли все наложенные на них наказания:

(28) Раньшь поп питиньё наложыт и фсё спалняли, гриха баялись (Летки, Старошайговский район).

В русских говорах Мордовии зафиксированы различные наименования, связанные с постом и ограничением человека в пище: 
загванье - 'последний день перед постом, когда верующим разрешается есть скоромное; заговенье', петровка - 'пост перед Петровым днем', успленский - 'Успенский (пост)':

(29) Апасля загвънья пост, скаромнъя ни идят (Анненково, Ромодановский район);

(30) Сначалъ идёт Успленскъй пост две недели (Суподеевка, Ардатовский район).

\section{Наименования сезонных праздников}

Сезонные праздники на Руси были связаны с земледельческими традициями далеких предков восточных славян. Знаковыми в сознании сельского жителя становились переходы от одного времени года к другому, поскольку эти периоды обозначали важные события в жизни крестьянина: окончание зимы, начало посевной, сбор урожая и др. Неслучайно в традиционной русской культуре сохранились наименования праздников, посвященных проводам того или иного времени года.

Весна в народном календаре знаменовала собой начало активного периода в жизни человека, возобновление сельскохозяйственных работ. В православной культуре считалось, что весна символизирует победу жизни над смертью, добра над злом. На Руси до XIV в. наступление нового года отмечали весной, в день весеннего равноденствия. Важным событием считался переход от зимы к весне, поэтому на Руси широко отмечались проводы зимы. В говорах сохранилось название праздника проводов зимы, Масленицы ма́слена в 3-м знач. Старинный славянский праздник проводов зимы обозначался глаголом масловать:

(31) Эх и любили бывалъчи мъславать, с утра маслуим, фсю ниделю мъславали (Старая Михайловка, Ромодановский район).

Многочисленные праздники отмечаются в мае, так как этот месяц характеризуется активным ростом и цветением растений, переходом к сельскохозяйственным работам, первым выгоном скота в поле. Праздник, связанный с проводами весны, принадлежит к сельским обрядам и сопровождается массо- выми гуляньями. В народной среде он называется люлё, полюлё, ярило, яриль:

(32) Вот как вясна кончаццъ, дефки дъ парни рядюццъ, песни поют, празник этъ у нас, люлё (Большие Поляны, Ардатовский район).

Проводы весны празднуют в течение всей последней недели мая (по старому календарю), которую называют гулящая неделя:

(33) Фсю гулящую ниделю висну красну пръважали (Тенишево, Краснослободский район).

Весенний праздник кочетки́ отмечается 22 мая, в этот день принято обливаться водой:

(34) Дваццъть фтаровъ мая па-новъму фсе вадой абливаюццъ. Этът празник у нас нъзываццъ кыцытки (Мельцаны, Старошайговский район).

В диалектной среде посредством устойчивого сочетания сухой игриш также фиксируется народная забава: обливание на улице любого человека водой на следующий день после праздника - проводов весны.

Праздник последнего дня весны в исследуемых говорах получил название русалкино (русальское) загванье:

(35) Нъ русалкинъ загвънья в лес ходют, винки зъвивают (Дмитриев Усад, Атюрьевский район).

Данный фразеологизм употребляется и в шутливой форме, если речь идет о времени, которое наступит неизвестно когда:

(36) Сказала иму, штоп саломки принёс, дъ вить надеждъ-тъ нъ ниво плахая, дъ русалкина загвънья ждать придёццъ (Кулишейка, Рузаевский район).

Проводы лета и наступление осени, окончание летнего сезона - времени активного сельскохозяйственного труда, связанного с обработкой урожая, - означал такой сельский праздник, как федраська:

(37) Фидраськь прайдёт, а там - осинь. Ванькъ, я нъ фидраську эх ы нъгуляюсь! (Старая Фёдоровка, Старошайговский район).

Осень в крестьянском календаре связана с уборочной страдой, сбором грибов, пополнением продовольственных запасов и под- 


\section{РАЗВИТИЕ И ФУНКЦИОНИРОВАНИЕ РУССКОГО ЯЗЫКА}

готовкой к зиме. Завершается длительный период полевых работ, который начался ранней весной с возделывания участков и посева. Особое значение в крестьянской среде уделялось последнему дню жатвы, так как он о3наменовывал окончание тяжелых полевых работ. В этот день устраивался праздник дожин$\kappa и$ в 1-м знач., пожинки - 'последний день жатвы и праздник по этому поводу’:

(38) Раньшъ пажынки в радъсть были (Сиалеевская Пятина, Инсарский район);

(39) Как толькъ дажынки, то Матрёнкъ с утра петь ф поли нъчиналъ (Усыскино, Инсарский район).

По данным исследуемых говоров, был распространен обряд жечь серафо́нку, это ритуальное действие обозначало символические проводы осени, когда молодежь делала чучело из соломы, одевала его в лохмотья и сжигала.

Среди народных праздников зимнего цикла отмечается череда предновогодних и последующих январских гуляний. Так, диалектные наименования овсень, усеньки, ${ }^{2}$ усенька в 1-м знач. репрезентируют канун нового года, когда молодежь с песнями-колядками ходит по домам, получая подарки и угощение:

(40) Нъ усеньки блины пякут, рибятишки ракульку пают, а вечиръм салому жгут (Черемис, Ковылкинский район).

\section{Наименования обрядов}

В русских говорах на территории Республики Мордовия сохранились наименования различных обрядов, знаменовавших изменение социального статуса человека, переход его в иное состояние. Свадебный обряд является одним из самых ярких и красивых в традиционной русской культуре; он до сих пор хранит в себе архаические черты, восходящие к славянской древности, и характерные локальные признаки. Анализ свадебной лексики и фразеологии способствует пониманию специфических черт народного быта, особенностей взаимоотношений между представителями территориально замкнутого социума. Свадебный обряд был длительным по времени проведения, поэтому в нем можно выделить несколько основных этапов: предсвадебный, свадебный и послесвадебный.
До того как состоится свадьба, обязательным было знакомство родителей, получение их благословения. Первое знакомство родственников жениха и невесты называлось в сельской местности рукоби́тье. Обряд знакомства жениха с невестой (смотрины), представленный лексемами ${ }^{2}$ гляделки, поглядье, поглядки, собирал множество зрителей:

(41) Вывидут нъ глиделки, тут уш фсё и ришыццъ. Нъ глиделкъх многъ падрук събирёццъ (Новая Резеповка, Ковылкинский район).

Обычай, когда родственники невесты ходили к жениху, чтобы договориться о дне свадьбы, в диалектной среде номинируют устойчивые сочетания с лаптями ходить (идти), лапти давать. Решение сыграть свадьбу и объявление кого-либо женихом и невестой называли первый зной или поклон:

(42) Када замуш выходют, радня придёт нъ паклон (Шишкеево, Рузаевский район).

Устойчивое сочетание пойти́ на покло́н, которое сопровождается в СРГРМ пометой ycmap., обозначало в говорах такой обязательный процесс свадебного обряда, как пойти к родителям невесты за благословением. После состоявшегося сватовства устраивали запой, ${ }^{1}$ курник в 3-м знач., ${ }^{2}$ стоянку - собрание гостей у невесты:

(43) Ва время запоя дъгаваривъюццъ, кады свадьбу играть, етъ уш абычий такой (Усыскино, Инсарский район).

Кроме того, в исследуемых говорах зафиксированы фразеологические единицы поиграть вечёрку - 'принять участие в свадебном обряде, вечеринке у невесты после сватовства', пропивать (пропить) невесту 'устраивать (устроить) выпивку в ознаменование состоявшегося сватовства'

Особое значение уделялось сохранившейся с древнейших времен традиции, когда подруги невесты несут в дом жениха накануне свадьбы украшенную цветами ветку, - цветок нести (понести). Ритуальные действия украшения куста или ветки совершались участниками свадебного обряда заранее, как правило, накануне вечером, в говорах сохранились такие упоминания об этом процессе: наряжать 
peneй - 'украшать цветами и лентами куст репейника, который «продают» вместе с невестой', куст рядить - 'украшать лентами и цветами ветку дерева'.

Перед свадьбой соединялось имущество будущих молодоженов, поэтому существовал обряд носить (понести) рубашку, когда подруги невесты накануне свадьбы несли в дом жениха подарки от невесты:

(44) Насить рубашку ходют самыи блискии падруги нивесты. Пайду пъсматрю: к Марозъвым рубашку пънисли (Тепловка, Кочкуровский район).

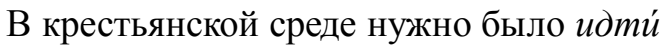
c ме́ркой в дом жениха, чтобы измерять окна и двери, а потом шить занавески. Принято было также родственникам или подругам невесты осматривать перед свадьбой имущество жениха - оглядывать кольшки, смотреть печурки:

(45) У нас и щас абычий такой: пирит свадьбъй свахъ колышки аглядывът у жъниха (Гумны, Краснослободский район).

Предсвадебный этап предполагает прощание девушки с незамужней жизнью, поэтому зафиксированные наименования вечерён$\kappa a$, вечёрка, сваха, сёстра, вечеринка, вечеренька, а также устойчивое сочетание ходить в подруги обозначают девичник в доме невесты накануне свадьбы. Вечер непосредственно перед свадьбой называется в изучаемых говорах nозываты, так как на такие посиделки созывались друзья невесты и жениха. Средствами фразеологии репрезентируется такой элемент свадебного обряда, как мягчать neрину: подруги невесты оставались ночевать у невесты накануне свадьбы:

(46) Вечиръм пришли падруги мякчять пирину (Ключарёво, Рузаевский район).

Обычай сопровождать свадебный обряд на всем протяжении плачем и причитаниями был распространен на Руси повсеместно. Н.Ю. Таратынова отмечает обязательное исполнение плачей-причитаний на свадьбе, так как «в момент традиционной свадьбы невеста как центральное действующее лицо всего обряда изменяла свой социальный статус и навсегда покидала родную семью, дом, а так- же резко меняла образ жизни, расставалась с подругами» [Таратынова, 2006, с. 312]. Проводы уходящей беззаботной жизни сопровождались плачем и причитаниями самой невесты, что подтверждает иллюстративный материал:

(47) Фсю вичиреньку нивестъ плачит и причитат (Ирсеть, Старошайговский район).

Глагольные лексемы вызванивать, привоплять, вопить, корить (в одном из значений) выражают громкий плач невесты, сопровождающийся причитаниями. Устойчивые сочетания волюшку вопить, красу отдавать также указывают на обычай громко причитать перед свадьбой, оплакивая девичью волю:

(48) Невесть пирет свадьбъй привоплят (Грибоедово, Кочкуровский район).

Свадебный обряд на всем протяжении сопровождался также исполнением ритуальных песен, имеющих сакральный смысл. Так, фразеологическая единица шапочку петь указывает на исполнение песни жениху. В русских говорах Мордовии зафиксирован глагол корить, в одном из значений номинирующий обрядовый процесс восхваления пением. Хвалебная песня могла быть посвящена родителям, жениху или невесте:

(49) А патом жьниха карить начьнут (Алексеевка, Темниковский район);

(50) Мъладыи ищё радитилий карят (Стрелецкая Слобода, Рузаевский район).

В русских говорах Мордовии употребляются различные наименования, обозначающие вступление в брак: лексико-фонетические диалектизмы свальба, сварьба (в одном из значений) - 'свадьба', лексико-словообразовательные диалектизмы женатство, поженитьба - 'женитьба'. Лексема отпи́рки называет последний день свадьбы. Наименования поезженина, поезжина в 1-м знач. характеризуют свадебный поезд. На совершение свадебного обряда указывает глагольная лексема курничать, устойчивое сочетание заиграть свадьбу обозначает завершение этого процесса - 'сыграть свадьбу'. 


\section{РАЗВИТИЕ И ФУНКЦИОНИРОВАНИЕ РУССКОГО ЯЗЫКА}

Часть свадебного обряда представляла собой своеобразную торговлю, поскольку жениху или гостям необходимо было совершить выкуп, заплатить за что-либо. Для номинации подобных этапов обряда в говорах употребляются такие фразеологические единицы, как окупать ворота, откупать (покупа́ть) невесту - 'родственники жениха выкупают невесту', кладку драть - 'выкупать приданое невесты', козла окупать - 'приглашенные на свадьбу платят за вино, выпитое из обвязанного красной лентой стакана':

(51) Пъкупат нивесту друшкъ, а жыних токъ ръспърижаццъ, сколькъ дать. У нас фсягда нивесту пъкупают, а ищё пъкупают двери, месть нивестинь дъ туфильку иё (Петровка, Дубенский район).

Для обозначения получения выкупа за невесту в свадебном обряде употребляется диалектизм накорить. Со стороны невесты также были определенные обязательства, поэтому она приходила в семью жениха не с пустыми руками. Так, принято было везти коробью - 'везти приданое невесты к жениху', дарить на поклон - 'невесте одаривать родных жениха'. Диалектоносители отмечают, что с течением времени традиции одаривания могут меняться:

(52) Нъ паклон раньшъ был. А сичяс нивесту адаривъют, фсё нъабарот (Павловка, Старошайговский район).

Приглашенные на свадьбу родственники и друзья дарили подарки молодым, этот этап свадебного обряда представляет устойчивое сочетание сыр метать:

(53) А таперь давайти сыр мятать для мъладых. Свахъ, чяшку, чяшку дай-къ суды, сыр мятать будим (Куликово, Тенгьгушевский район).

Диалектная фразеология номинирует различные ритуальные обрядовые действия, совершавшиеся в день свадьбы: в избе зажигали солому, а невеста с женихом должны были тушить огонь. Обряд овин тушить обозначал окончательный уход молодой жены из родительской семьи к мужу. Славянская традиция осыпать молодых хмелем после венчания - окуnывать молодық - уходит корнями в далекое прошлое и символизирует пожелание молодым счастья и благоденствия.
В составе изучаемой диалектной фразеологии зафиксированы такие обрядовые действия, как поехать (ехать) с повесткой 'предупреждение невесты о скором прибытии жениха', в горны́ звать - 'приглашать родственников невесты в дом жениха в день свадьбы', в горны́ идти́ (пойтú, ходи́mь, nрuéxaть) - 'идти (пойти) к жениху в день свадьбы (о родственниках невесты)'. В русских деревнях было принято пировать, отмечая различные этапы свадебного обряда: $n e$ регу́лки - 'взаимное угощение новых родственников после свадьбы', ми́лло вози́ть 'устраивать пирушку у родственников невесты спустя некоторое время после свадьбы'. В диалектной среде проводы жениха и невесты в церковь называли второй запой, а пир у молодых после венчания - горно́й (в одном из значений), горнй (в одном из значений), горна́й:

(54) При горном бьют горшки, стаканы, толькь пряч фсё. Мы вот смотрим нынишны свадьбы, горной уш режы стал, по-новъму играют (Манадыши, Атяшевский район).

В рамках послесвадебного этапа особое значение имел второй день после свадьбы. Рано утром идут ярку искать - искать невесту в доме жениха.

В этот день считалось обязательным на блинки звать, то есть приглашать в гости родственников жениха в дом родителей невесты, а родственникам жениха, соответственно, идти в дом родителей невесты идти на блинки (пирожки). На второй день свадьбы из дома невесты к жениху несут украшенный лентами и цветами куст, ветку сосны. Данный элемент свадебного обряда в диалектной лингвокультуре представлен устойчивым сочетанием курник нести (понести), сосну нести:

(55) Сасну нясут ряжъны и гъварят жъниху: «Нашъ яркъ таке вот ленты насилъ». Носют сасну утръм, а патом гости жъниха идут гулять к нивести (Петровка, Дубенский район);

(56) Нъ фтарой день у нас курник нисут самыи блиски и радныи нивесты (Тепловка, Кочкуровский район).

Похоронный обряд, как и свадебный, принадлежит к числу наиболее архаических и сохраняет многие черты традиционных воз- 
зрений человека на смерть. «Соблюдение такого важного обряда, каким является похороннопоминальный, строго контролировалось в традиционной русской деревне общественным мнением и этическими нормами, поэтому он долгое время оставался без изменений и до сих пор сохраняется во многих местах России» [Букринская, Кармакова 2013, с. 74]. В этнолингвистических исследованиях нередко отмечается общность свадебного и похоронного обрядов, что объясняется их «переходным» характером [Маслова, Мочалова 2013, c. 61].

Современный похоронный обряд сохраняет черты старого, еще языческого процесca, однако магическое содержание обрядового действа во многом утратилось. Это проявляется в том, что в диалектном корпусе русских говоров Мордовии представлено небольшое количество лексических и фразеологических единиц, номинирующих похороннопоминальные обряды.

Лексические единицы покорон, смертник обозначают похороны, фразеологизмы отнести за сторожёвых, сделать траур называют сам процесс - 'схоронить, похоронить'. Наиболее многочисленна группа слов погребальнопоминального ритуала, связанных с номинацией поминок. Лексемы канун в 1-м знач., ${ }^{1}$ nóuлина в 1-м знач. имеют обобщенное значение 'поминки', в то время как большая часть языковых единиц содержит в своей смысловой структуре дифференциальные компоненты значения, конкретизирующие определенные временные отрезки: горячий стол в 1-м знач. ‘поминки после похорон', шестина - 'поминки по умершему через шесть недель после смерти', година - 'поминки в годовщину смерти кого-либо’:

(57) Коли чъловек умрёт, об нём делъют поминки. Эти поминки нъзываюцць горячым столом. Нъ горячый стол чыловек фсю жызню пръроботьл, поэтъму нъ горячый стол угошчают вином, тут не грех ы выпить, нъ другех поминкъх пить нельзя (Суподеевка, Ардатовский район).

Отдельные лексические единицы репрезентируют обрядовые комплексы, составляющие обязательную структуру погребальнопоминального ритуала в соответствии с православными традициями и имеющие сакраль- ное значение для верующего: панафида, канун в 4-м знач. - 'церковная служба по умершему, панихида', опевать - 'совершать обряд отпевания'. Это подтверждает, что для человека важно, чтобы его похоронили с соблюдением обрядовых действий. Фразеологическая единица свалить на коноклёску 'похоронить без обряда' - содержит пренебрежительный оттенок:

(58) Этъ у миня ф сундуке-ти смертнъй узил, в нём платья, покрой, а то пьпадёш ф пристарелый дом, кто чай тея там събирать-ть будит. Покроют какем-нибуть савънъм дъ свалют път кънаклёску (Суподеевка, Ардатовский район).

В поминальные дни люди обязательно посещали могилы родственников, принося с собой еду, вино, чтобы пригласить усопшего на ритуальную трапезу. Фразеологизм завтрак на кладбище носить - 'поминать'- сохранил обычай, оставшийся от древнего похоронного обряда, который предусматривал задабривание душ умерших.

В православной традиции существовали специальные дни поминовения умерших родители, поминуща. В такие дни в соответствии с обычами и обрядам поминального цикла требовалось проявление заботы об умерших в виде специальных молений, особых трапез, посещения могил:

(59) Сиводни радитили, на кладбища пайдём. Нъ радитили мы пъминаим умершых (Новое Баево, Большеигнатовский район).

Христианский обряд крещения кого-либо номинируют в исследуемых говорах единичные лексические единицы ксти́ны, кще́нье (в одном из значений). В этот день принято было собираться родственникам, готовить обрядовые угощения, дарить подарки:

(60) Бывалъчи у фсех кстины были, так уш зъвидяно былъ. Как кстины, так гулянкъ. Ишто зъ заправъ такая? (Гумны, Краснослободский район).

\section{Заключение}

Проведенное исследование показало, что диалектные наименования праздников и обрядов представляют сложный и уникальный компонент традиционной культуры, который зани- 
мает значительное место в лингвосознании русского народа. Наиболее многочисленными в говорах являются наименования, связанные со свадебными обрядами, а также номинации календарных религиозных и сезонных праздников. Обозначения похоронных и поминальных обрядов представлены небольшим количеством лексических и фразеологических единиц и репрезентируют обрядовые действия довольно обобщенно, практически не дифференцируя этапы совершения ритуала.

Таким образом, названия календарных праздников и народных обрядов в русских говорах отражают культурно-исторические традиции, верования, обычаи представителей территориально замкнутого социума, являются способами репрезентации этнокультурного сознания русского народа. Они представляют особую форму хранения и отражения национально-культурной информации, становятся основой для порождения символических значений в ценностносмысловом пространстве этноса.

\section{СПИСОК ЛИТЕРАТУРЫ}

Акимова Э. Н., Маслова А. Ю., Мочалова Т. И., 2014. Этнолингвокультурологическая интерпретация бытовой и обрядовой фразеологии русских говоров Республики Мордовия // Современное состояние и перспективные векторы развития филологии, лингвистики, языкознания и коммуникативистики. В 3 т. Т. 1. Ростов н/Д : Науч. сотрудничество. С. 73-99.

Байбурин А. К., 1993. Ритуал в традиционной культуре: структурно-семантический анализ восточнославянских обрядов. СПб. : Наука. 206 с.

Банкова Т. Б., 1998. Словарь сибирских обрядов: к постановке проблемы // Проблемы лексикографии, мотивологии, дериватологии. Томск : Изд-во ТГУ. С. 22-33.

Бахвалова Т. В., 2015. Представление зимнего цикла календарных обрядов в орловских говоpax // Ученые записки Орловского государственного университета. Серия «Гуманитарные и социальные науки». № 3 (66). С. 87-89.

Букринская И. А., Кармакова О. Е., 2013. Глаголы со значением «исполнять похоронный обрядовый плач» в русских говорах // Лексический атлас русских народных говоров : Материалы и исследования 2013. СПб. : Нестор-История. С. 74-83.
Гайсина Ю. В., 2007. Свадебный обряд в селе Стояново // Тульская область. Одоевский край. Очерки прошлого и настоящего. М. : Ин-т наследия. С. 338-367.

Гура А. В., 2012. Брак и свадьба в славянской народной культуре // Семантика и символика. М. : Индрик. $936 \mathrm{c.}$

Житникова М. Л., 2006. Лексика свадебного обряда как источник изучения народной культуры // Язык и культура : сб. ст. XVIII Междунар. науч. конф., посвящ. 10-летнему юбилею фак. иностр. яз. (Томск, 18-20 апр. 2005 г.). Том. гос. ун-та. Томск : Изд-во ТГУ. C. $36-40$.

Зубова Ж. А., 2006. Отражение во фразеологии орловских говоров народных праздников, обрядов, обычаев и суеверий // Экология культуры и языка: проблемы и перспективы. Архангельск : Изд-во ПГУ. С. 224-229.

Костромичёва М. В., 2007. Лексика народного календаря // Лексический атлас русских народных говоров : Материалы и исследования 2007. СПб. : Наука. С. 351-356.

Кузнецова И. В., 1999. Календарная обрядность и устойчивые сравнения // Коммуникативнопрагматические аспекты фразеологии : тез. докл. Междунар. конф. (Волгоград, 28-29 сент. 1999 г.). Волгоград : Перемена. С. 153-155.

Лотман Ю. М., Успенский Б. А., 1971. О семиотическом аспекте культуры // Ученые записки Тартуского государственного университета. Вып. 284 : Труды по знаковым системам. C. 144-166.

Маслова А. Ю., Мочалова Т. И., 2013. Этнолингвистическая репрезентация обрядовой деятельности во фразеологии русских говоров Республики Мордовия // Финно-угорский мир. № 2 (15). С. 59-63.

Меркулова В. И., 1994. Календарная и обрядовая лексика, связанная с весенними христианскими праздниками в говорах Орловской области // Духовная культура: проблемы и тенденции развития : Всероссийская научная конференция (Сыктывкар, 11-14 мая 1994 г.) : тез. докл. Сыктывкар : Изд-во СГУ. С. 72-75.

Миронович М. С., 2012. Наименования участников свадебного обряда Калужской области // Лексический атлас русских народных говоров : Материалы и исследования 2012. СПб. : Нестор-История. С. 332-337.

Мочалова Т. И., Маслова А. Ю., 2014. Репрезентация языческого и христианского мировоззрения во фразеологии русских говоров Республики Мордовия // Русский язык: исторические судьбы и современность : тр. и материалы $\mathrm{V}$ Междунар. конгр. исследователей рус. яз. 
(Москва, 18-21 марта 2014 г.). М. : Изд-во МГУ. С. 123-124.

Таратынова Н. Ю., 2006. К вопросу о номинации обрядового свадебного причитания (по материалам псковских говоров) // Лексический атлас русских народных говоров : Материалы и исследования 2006. СПб. : Наука. С. 309-314.

Тихомирова Н. П., 2008. Лексика календарных обрядов в белозерских говорах // Лексический атлас русских народных говоров : Материалы и исследования 2008. СПб. : Наука. С. 241-247.

Фомичева С. В., 2012. Символика предметного кода свадебного обряда (на материале тульских говоров) // Лексический атлас русских народных говоров : Материалы и исследования 2012. СПб. : Нестор-История. С. 326-331.

Человек и его мир в диалектной фразеологии русских говоров Мордовии / Э. Н. Акимова, А. Ю. Маслова, Т. И. Мочалова [и др.]. Саранск : Изд-во Мордов. ун-та, 2015. 156 с.

Чухарева Г. В., 1978. Из наблюдений над лексикой и фразеологией свадебных обрядов нескольких сел Курганского района Красноярского края // Вопросы исследования лексики и фразеологии Сибирских говоров. Красноярск : Изд-во КГУ. С. 21-27.

Штейнгарт Л. М., 2006. Особенности репрезентации языковой картины мира российских немцев (на материале пословиц и поговорок) : автореф. дис. ... канд. филол. наук. Иркутск. 22 с.

\section{ИСТОЧНИК}

СРГРМ - Словарь русских говоров на территории Республики Мордовия. В 2 ч. / Ин-т лингв. исслед. РАН. СПб. : Наука, 2013. Ч. 1. 672 с. Ч. 2. С. $673-1560$.

\section{REFERENCES}

Akimova E.N., Maslova A.Yu., Mochalova T.I., 2014. Etnolingvokulturologicheskaya interpretatsiya bytovoy i obryadovoy frazeologii russkih govorov Respubliki Mordoviya [Ethnical Linguistic Culturological Interpretation of Everyday and Ritual Phraseology of Russian Dialects of the Republic of Mordovia]. Sovremennoe sostoyanie i perspektivnye vektory razvitiya filologii, lingvistiki, yazykoznaniya i kommunikativistiki. V 3 t. T. 1 [The Current State and Promising Vectors of Development of Philology, Linguistics and Communication Studies. In 3 Vols. Vol. 1].
Rostov-on-Don, Nauchnoe sotrudnichestvo Publ., pp. 73-99.

Baiburin A.K., 1993. Ritual v traditsionnoy kulture: strukturno-semanticheskiy analiz vostochnoslavyanskih obryadov [Ritual in Traditional Culture: Structural and Semantic Analysis of East Slavic Rites]. Saint Petersburg, Nauka Publ. 206 p.

Bankova T.B., 1998. Slovar sibirskih obryadov: k postanovke problemy [Dictionary of Siberian Rites: To the Formulation of the Problem]. Problemy leksikografii, motivologii, derivatologii [Problems of Lexicography, Motivology, Derivatology]. Tomsk, Izd-vo TGU, pp. 22-33.

Bakhvalova T.V., 2015. Predstavlenie zimnego tsikla kalendarnykh obryadov $\mathrm{v}$ orlovskikh govorakh [Presentation of the Winter Cycle of Calendar Rites in the Orel Dialects]. Uchenye zapiski Orlovskogo gosudarstvennogo universiteta. Seriya «Gumanitarnye $i$ sotsialnye nauki» [Scientific Notes of the Oryol State University. Series "Humanities and Social Sciences"], no. 3 (66), pp. 87-89.

Bukrinskaya I.A., Karmakova O.E., 2013. Glagoly so znacheniem «ispolnyat pokhoronnyy obryadovyy plach» v russkikh govorakh [Russian Dialects: Verbs with the Meaning “To Perform a Funeral Ritual Lament" in Russian Dialects]. Leksicheskiy atlas russkikh narodnykh govorov: Materialy i issledovaniya 2013 [Lexical Atlas of Russian Folk Dialects. Materials and Research 2013]. Saint Petersburg, Nestor-Istoriya Publ., pp. 74-83.

Gaisina Yu.V., 2007. Svadebnyy obryad v sele Stoyanovo [Wedding Ceremony in the Village of Stoyanovo]. Tulskaya oblast. Odoevskiy kray. Ocherki proshlogo $i$ nastoyashchego [Tula Region. Odoyevsky Krai. Essays of the Past and Present]. Moscow, Institut naslediya, pp. 338-367.

Gura A.V., 2012. Brak i svadba v slavyanskoy narodnoy kulture [Marriage and Wedding in Slavic Folk Culture]. Semantika i simvolika [Semantics and Symbolism]. Moscow, Indrik Publ. 936 p.

Zhitnikova M.L., 2006. Leksika svadebnogo obryada kak istochnik izucheniya narodnoy kultury [Wedding Ceremony Vocabulary as a Source for Studying Folk Culture]. Yazyk i kultura: sb. st. XVIII Mezhdunar. nauch. konf., posvyashch. 10-letnemu yubileyu fak. inostr. yaz. Tom. gos. un-ta [Language and Culture. Collection of Articles of the $18^{\text {th }}$ International Scientific Conference Dedicated to the $10^{\text {th }}$ Anniversary of the Faculty of Foreign Languages of Tomsk State University]. Tomsk, Izd-vo TGU, pp. 36-40. 
Zubova Zh.A., 2006. Otrazhenie vo frazeologii orlovskikh govorov narodnykh prazdnikov, obryadov, obychaev i sueveriy [Reflection in the Phraseology of the Orel Dialects of Folk Holidays, Rituals, Customs and Superstitions]. Yekologiya kultury i yazyka: problemy $i$ perspektivy [Ecology of Culture and Language: Problems and Prospects]. Arkhangelsk, Izd-vo PGU, pp. 224-229.

Kostromicheva M.V., 2007. Leksika narodnogo kalendarya [The Lexicon of the Popular Calendar]. Leksicheskiy atlas russkikh narodnykh govorov: Materialy i issledovaniya 2007 [Lexical Atlas of Russian Folk Dialects. Materials and Research 2007]. Saint Petersburg, Nauka Publ., pp. 351-356.

Kuznetsova I.V., 1999. Kalendarnaya obryadnost i ustoychivye sravneniya [Calendar Rites and Stable Comparisons]. Kommunikativnopragmaticheskie aspekty frazeologii: tez. dokl. Mezhdunar. konf. (Volgograd, 28-29 sent. 1999 g.) [Communicative and Pragmatic Aspects of Phraseology. Abstracts of Reports of the International Conference (Volgograd, September 28-29, 1999)]. Volgograd, Peremena Publ., pp. 153-155.

Lotman Yu.M., Uspensky B.A., 1971. O semioticheskom aspekte kultury [On the Semiotic Aspect of Culture]. Uchenye zapiski Tartuskogo gosudarstvennogo universiteta. Vyp. 284: Trudy po znakovym sistemam [Scientific Notes of the Tartu State University. Iss. 284. Proceedings on Sign Systems], pp. 144-166.

Maslova A.Yu., Mochalova T.I., 2013. Etnolingvisticheskaya reprezentatsiya obryadovoy deyatelnosti vo frazeologii russkikh govorov Respubliki Mordoviya [Ethnic Linguistic Representation of Ritual Activity in the Phraseology of Russian Dialects of the Republic of Mordovia]. Finno-ugorskiy mir [Finno-Ugric World], no. 2 (15), pp. 59-63.

Merkulova V.I., 1994. Kalendarnaya i obryadovaya leksika, svyazannaya s vesennimi khristianskimi prazdnikami v govorakh Orlovskoy oblasti [Ritual Calendar and the Vocabulary Associated with the Spring Festivals in the Christian Dialects of the Orel Region]. Duhovnaya kultura: problemy i tendentsii razvitiya: Vserossiyskaya nauchnaya konferentsiya: tez. dokl. [Spiritual Culture: Problems and Development Trends. AllRussian Scientific Conference. Abstracts of Reports]. Syktyvkar, Izd-vo SGU, pp. 72-75.

Mironovich M.S., 2012. Naimenovaniya uchastnikov svadebnogo obryada Kaluzhskoy oblasti [Names of Participants in the Wedding Ceremony of the Kaluga Region]. Leksicheskiy atlas russkikh narodnykh govorov: Materialy $i$ issledovaniya 2012 [Lexical Atlas of Russian Folk Dialects. Materials and Research 2012]. Saint Petersburg, Nestor-Istoriya Publ., pp. 332-337.

Mochalova T.I., Maslova A.Yu., 2014. Reprezentatsiya yazycheskogo i khristianskogo mirovozzreniya vo frazeologii russkikh govorov Respubliki Mordoviya [Representation of the Pagan and Christian Worldview in the Phraseology of Russian Dialects of the Republic of Mordovia]. Russkiy yazyk: istoricheskie sudby $i$ sovremennost: tr. i materialy $V$ Mezhdunar. kongr. issledovateley rus. yaz. (Moskva, 1821 marta 2014 g.) [Russian Language: Historical Fate and Modernity. Proceedings and Materials of the V International Congress of Russian Language Researchers (Moscow, March 18-21, 2014)]. Moscow, Izd-vo MGU, pp. 123-124.

Taratynova N.Yu., 2006. K voprosu o nominatsii obryadovogo svadebnogo prichitaniya (po materialam pskovskikh govorov) [On the Issue of the Nomination of the Ceremonial Wedding Lamentation (Based on the Materials of Pskov Dialects)]. Leksicheskiy atlas russkikh narodnykh govorov: Materialy i issledovaniya 2006 [Lexical Atlas of Russian Folk Dialects. Materials and Research 2006]. Saint Petersburg, Nauka Publ., pp. 309-314.

Tikhomirova N.P., 2008. Leksika kalendarnykh obryadov v belozerskikh govorakh [Vocabulary of Calendar Rites in Central Dialects]. Leksicheskiy atlas russkikh narodnykh govorov. Materialy i issledovaniya 2008 [Lexical Atlas of Russian Folk Dialects. Materials and Research 2008]. Saint Petersburg, Nauka Publ., pp. 241-247.

Fomicheva S.V., 2012. Simvolika predmetnogo koda svadebnogo obryada (na materiale tulskikh govorov) [Symbolism of the Subject Code of the Wedding Ceremony (On the Material of Tula Dialects)]. Leksicheskiy atlas russkikh narodnykh govorov: Materialy i issledovaniya 2012 [Lexical Atlas of Russian Folk Dialects. Materials and Research 2012]. Saint Petersburg, Nestor-Istoriya Publ., pp. 326-331.

Akimova E.N., Maslova A.Yu., Mochalova T.I., Ershova N.I., Denisova L.N. et al., 2015. Chelovek $i$ ego mir $v$ dialektnoy frazeologii russkih govorov Mordovii [Man and His World in the Dialect Phraseology of Russian Dialects of Mordovia]. Saransk, Izd-vo Mordovskogo universiteta. $156 \mathrm{p}$.

Chukhareva G.V., 1978. Iz nablyudeniy nad leksikoy i frazeologiey svadebnykh obryadov neskolkikh sel Kurganskogo rayona Krasnoyarskogo kraya [From Observations on the Vocabulary and 
Phraseology of Wedding Ceremonies in Several Villages of the Kurgan District of the Krasnoyarsk Territory]. Voprosy issledovaniya leksiki i frazeologii Sibirskikh govorov [Questions of the Study of the Vocabulary and Phraseology of Siberian Dialects]. Krasnoyarsk, Izd-vo KGU, pp. 21-27.

Shteingart L.M., 2006. Osobennosti reprezentatsii yazykovoy kartiny mira rossiyskikh nemtsev (na materiale poslovits i pogovorok): avtoref. dis... kand. filol. nauk [Features of the Representation of the Linguistic Picture of the
World of Russian Germans (On the Material of Proverbs and Sayings). Cand. philol. sci. abs. diss.]. Irkutsk. 22 p.

\section{SOURCE}

Slovar russkikh govorov na territorii Respubliki Mordoviya. V $2 \mathrm{ch}$. [Dictionary of Russian Dialects on the Territory of the Republic of Mordovia. In 2 Pts.]. Saint Petersburg, Nauka Publ., 2013, pt. 1.672 p.; pt. 2, pp. 673-1560.

\section{Information About the Authors}

Elvira N. Akimova, Doctor of Sciences (Philology), Professor, Department of Russian Philology and Cross Cultural Communication, Pushkin State Russian Language Institute, Akademika Volgina St, 6, 117485 Moscow, Russia, akimovaen@mail.ru, https://orcid.org/0000-0002-0883-2173

Tatiana I. Mochalova, Candidate of Sciences (Philology), Associate Professor, Department of Russian Language, National Research Ogarev Mordovia State University, Bolshevistskaya St, 68/1, 430005 Saransk, Russia, mochalova2014@rambler.ru, https://orcid.org/0000-0003-1369-2985

\section{Информация об авторах}

Эльвира Николаевна Акимова, доктор филологических наук, профессор кафедры русской словесности и межкультурной коммуникации, Государственный институт русского языка им. А.С. Пушкина, ул. Академика Волгина, 6, 117485 г. Москва, Россия, akimovaen@mail.ru, https://orcid.org/0000-0002-0883-2173

Татьяна Ивановна Мочалова, кандидат филологических наук, доцент кафедры русского языка, Национальный исследовательский Мордовский государственный университет им. Н.П. Огарева, ул. Большевистская, 68/1, 430005 г. Саранск, Россия, mochalova2014@rambler.ru, https://orcid.org/0000-0003-1369-2985 